\title{
Estimativa da Composição Química Corporal de Tourinhos Santa Gertrudes a partir da Composição Química e Física das 9-10-11 a Costelas ${ }^{1}$
}

\section{Wignez Henrique ${ }^{2}$, Alexandre Amstalden Moraes Sampaio ${ }^{3}$, Paulo Roberto Leme ${ }^{4}$, Guilherme Fernando Alleoni ${ }^{5}$, Dante Pazzanese Duarte Lanna ${ }^{6}$}

\begin{abstract}
RESUMO - Foram obtidas equações de regressão linear simples para estimar a composição química corporal de bovinos Santa Gertrudes, a partir da composição química e física do corte das 9-10-11 a costelas. Quinze tourinhos, entre nove a 15 meses de idade e de 220 a $505 \mathrm{~kg}$ de peso, foram mantidos confinados. Os animais foram abatidos após jejum completo de 18 horas, sendo que seis deles foram abatidos após adaptação. A composição química em água, proteína, extrato etéreo e minerais foi determinada no corte das costelas e em amostras obtidas após moagem completa e homogeneização de todos os tecidos corporais, divididos em: sangue, couro, cabeça + patas, vísceras e carcaça. A composição física do corte das costelas foi obtida por separação manual do músculo, gordura e ossos. O peso do corpo vazio foi altamente correlacionado ao peso da carcaça quente $\left(\mathrm{r}^{2}=0,99\right)$. As porcentagens de água e extrato etéreo das 9-10-11 a costelas mostraram-se altamente correlacionadas com a composição química do corpo vazio, o que não ocorreu para as porcentagens de proteína e minerais. Esses teores foram calculados pela composição do corpo vazio desengordurado. A composição física do corte das costelas foi eficiente para estimar as porcentagens de água, extrato etéreo e minerais do corpo vazio, utilizando-se a porcentagem de gordura separável das costelas, mas não para estimar o teor de proteína. A composição física do corte das costelas demonstrou ser uma técnica eficiente, mas a composição química apresentou maiores coeficientes de determinação e menores erros da estimativa. Como a porcentagem de água no corpo vazio e no corte das costelas $\left(\mathrm{r}^{2}=0,95\right)$, e as porcentagens de água e de extrato etéreo no corpo vazio foram altamente correlacionadas $\left(\mathrm{r}^{2}=0,94\right)$, a porcentagem de água no corte das 9-10-11 a costelas poderia ser a única variável para estimativa da composição química corporal.
\end{abstract}

Palavras-chave: bovinos, composição do corpo vazio, determinação indireta

\section{Estimation of the Empty Body Chemical Composition of Santa Gertrudis Bulls Using the Chemical and Physical Composition of the 9-10-11 ${ }^{\text {th }}$ Ribs Cut}

ABSTRACT - Simple linear regressions to estimate empty body chemical composition of Santa Gertrudis young bulls were obtained, using the physical and chemical composition of the 9-10-11 th ribs cut. Fifteen intact males, from nine to fifteen months of age and from 220 to $505 \mathrm{~kg}$ of liveweight, were kept confined. They were slaughtered after 18 hours without water and food, and six of them were slaughtered after adaptation period. The content of water, protein, lipid and ash were determined on the ribs cut and on the blood, hide, head + feet, visceras and carcass, and samples were obtained after quantitatively grinding and homogenizing the entire tissue. The physical composition of the ribs was determined by manual separation of bone, lean and fat. Empty body weight was closely related to hot carcass weight $\left(r^{2}=0.99\right)$. Percent water and lipid of the 9-10-11 th ribs cut were closely related to the empty body chemical composition, but not to the percent protein and ash, that can be calculated from their proportions on the empty body without fat. The physical composition of the ribs cut was a good estimator of the empty body composition, mainly for the equations using separable ribs fat to estimate the contents of water, ether extract and ash, but not protein content. Despite the good results with the ribs cut physical composition, chemical composition was a more efficient estimator of empty body chemical composition, because the coefficients of determination were higher and the standard errors were lower. As the percentage of water in empty body was closely related to the water percent on $9-10-11^{\text {th }}$ ribs $\left(r^{2}=0.95\right)$ and the percentages of ether extract and water in the empty body $\left(r^{2}=0.94\right)$ were closely related each other, the water in the $9-10-11^{\text {th }}$ ribs cut alone can be used to estimate empty body composition.

Key Words: bovines, empty body composition, indirect determination

\footnotetext{
1 Parte da Tese de Doutoramento da primeira autora junto a FCAV/UNESP, Jaboticabal, SP.

2 Pesq. Científica, Instituto Zootecnia, São José do Rio Preto, SP, Bolsista CNPq. E.mail: wignez@terra.com.br

3 Professor, Depto. Zootecnia/FCAV/UNESP, Jaboticabal, SP, Bolsista CNPq. E.mail: sampaio@fcav.unesp.br

${ }^{4}$ Professor, Depto. Zootecnia/FZEA/USP, Pirassununga, SP, Bolsista CNPq. E.mail: prleme@usp.br

5 Pesquisador Científico, Instituto de Zootecnia, Nova Odessa, SP. E.mail: alleoni@izsp.br

6 Professor, Depto. Zootecnia/ESALQ/USP, Piracicaba, SP, Bolsista CNPq. E.mail: dplanna@esalq.usp.br
} 


\section{Introdução}

A determinação da composição corporal de bovinos é essencial em estudos de nutrição para avaliar alimentos e o crescimento animal. Pela composição corporal é possível e importante identificar alterações na composição do crescimento, em função de diversos fatores como raça, peso, sexo e composição da dieta; determinar a eficiência e as exigências nutricionais de diferentes categorias de animais, bem como avaliar o efeito de qualquer composto modificador do metabolismo.

É preciso diferenciar a composição da carcaça da composição química do corpo vazio ou corporal. Entende-se por corpo vazio todos os tecidos do animal, retirados os conteúdos do trato gastrintestinal e da bexiga e a bílis (Lofgreen et al., 1962).

Para a nutrição animal importa definir os componentes que possuem o mesmo valor calórico, independentemente dos tecidos onde são depositados. Assim, a composição química corporal refere-se às porcentagens de extrato etéreo, proteína, água e cinzas. A presença de carboidratos no corpo do animal é desconsiderada, pois esse teor é baixo e constante, ao redor de $0,7 \%$ na matéria seca (Reid et al., 1968).

$\mathrm{Na}$ determinação da composição corporal do animal após o abate, a forma direta deve ser entendida como a análise química de todos os tecidos do animal (Macneil, 1983).

Uma das técnicas de determinação direta da composição corporal é a moagem total dos tecidos do animal, e as amostras retiradas em seguida para análise (Leme et al., 1994; Lanna et al., 1995; Alleoni et al., 1997). Outra possibilidade é a amostragem proporcional dos tecidos antes da moagem (Estrada et al., 1997; Paulino et al., 1999; Jorge et al., 2000; Ferreira et al., 2001), mas esse procedimento parece estar mais sujeito à variações.

Em ambos os casos, os tecidos são separados em cinco partes: carcaça; cabeça e patas; couro; sangue; e vísceras. Essa última parte inclui retículorúmen, omaso-abomaso, intestinos, gordura renal pélvica inguinal, e outros órgãos (traquéia, pulmão, pâncreas, esôfago, coração, baço, fígado, rins, rabo e órgãos reprodutivos). Para as frações carcaça, cabeça, patas e couro, geralmente uma das metades é moída, esquerda ou direita, e a cabeça é serrada ao meio. As partes são pesadas separadamente, calculada a composição proporcional, e com a análise química de cada uma, determinada a composição química do animal.

Garret \& Hinman (1969) afirmaram que a determinação direta seria a forma mais confiável e precisa de medir a composição corporal. No entanto, quando se trabalha com animais de grande porte, o uso dessa técnica é dificultado pelo tempo exigido para a sua aplicação, alto custo e pela necessidade de infraestrutura adequada para sua realização. Assim, os esforços têm sido direcionados no sentido de desenvolver e aprimorar metodologias para a estimativa indireta. Lush (1926) utilizou os resultados de trabalhos de vários pesquisadores e determinou curvas de regressão entre os componentes químicos da carcaça e do corpo vazio em função dos mesmos componentes no corte da costela, obtendo coeficiente de determinação de 0,97 para o teor de gordura.

Hopper (1944) demonstrou que a utilização do corte das 9-10-11 $1^{\mathrm{a}}$ costelas para estimativa da composição da carcaça ou do corpo vazio gerava equações de regressão com menores quadrados médios do resíduo do que outros cortes de costela, sendo portanto mais indicado. $\mathrm{O}$ autor apontou a necessidade de estimar a composição corporal em relação ao peso vazio, e não a partir do peso em jejum, devido à variabilidade no enchimento do trato gastrintestinal.

O trabalho clássico que define a metodologia de utilização do corte das 9-10-11 1 - costelas foi realizado por Hankins \& Howe (1946). Esses autores estimaram a composição da carcaça a partir da composição da porção separável do corte das costelas, mas a mesma metodologia pode ser utilizada para estimativa da composição corporal. Foram utilizados 120 animais, machos e fêmeas, para a determinação das curvas de regressão; e foram obtidas correlações de 0,$83 ; 0,91$; e 0,53 , entre o corte das costelas 9-10-11 e a composição da carcaça, respectivamente para os teores de proteína, gordura e cinzas.

A composição do corte das costelas e a composição do corpo vazio podem ser correlacionadas quimicamente ou fisicamente. A composição química do corpo vazio estimada pela composição química do corte das costelas geralmente tem apresentado coeficientes de determinação ligeiramente mais elevados e menores coeficientes de variação (Lanna et al., 1995). Por outro lado, Alleoni et al. (1997) concluíram não haver diferença na estimativa da composição do corpo vazio a partir da análise química ou da separação física dos componentes. Os autores recomendaram o uso da separação física pela praticidade e pelos 
menores custos, uma vez que dispensa o uso de equipamentos e de reagentes.

Foi demonstrado nos trabalhos de Hopper (1944), Alhassan et al. (1975) e Robelin \& Geay (1975) que a melhor forma de estimar a porcentagem de água e de gordura do corpo vazio do animal era por meio da composição química do corte da costela, mas o mesmo não ocorria na estimativa da porcentagem de cinzas e de proteína. Lush (1926) já havia proposto que a estimativa desses dois componentes deveria ser de forma indireta, pela composição da matéria desengordurada, e Reid et al. (1968) concluíram que a composição do corpo vazio sem gordura seria relativamente constante.

Reid et al. (1955) também afirmaram que a composição corporal poderia ser estimada com precisão quando a quantidade de água ou de gordura do corpo fosse conhecida, uma vez que a composição do corpo vazio sem gordura seria praticamente constante, independentemente do grau de acabamento do animal. Mas Pearson et al. (1968) afirmaram que a conclusão anterior seria válida apenas para animais mais velhos, uma vez que a quantidade de água não era constante em animais jovens. Assim, tornou-se importante o conceito de "maturidade química", introduzido por Moulton (1923) e citado por Reid et al. (1955), que foi definido como a idade a partir da qual a concentração de água, proteína e matéria mineral nas células desengorduradas torna-se praticamente constante, validando a estimativa da composição corporal a partir da determinação do conteúdo de água ou de gordura no corpo vazio do animal.

Muitos trabalhos posteriores evidenciaram essa afirmativa, tais como os de Garret \& Hinman (1969) e Garret et al. (1971). No Brasil, Alleoni et al. (1997) concluíram que a utilização dos componentes do corte das 9-10-11 $\underline{\text { a }}$ costelas para estimar as porcentagens e as quantidades de água e extrato etéreo na carcaça e no corpo vazio apresentou altos coeficientes de determinação e baixos desvios-padrão da estimativa. Por outro lado, as estimativas para as porcentagens de proteína e cinzas e para a quantidade de cinzas apresentaram baixa precisão. Apesar disso, Peron et al. (1993), Jorge et al. (2000) e Ferreira et al. (2001) obtiveram, respectivamente, coeficientes de 0,$93 ; 0,84$; e 0,97 para a estimativa do teor de proteína no corpo vazio a partir do teor desse nutriente no corte das costelas 9-10-11․

Como haviam utilizado machos e fêmeas em seus experimentos, Hankins \& Howe (1946) concluíram que as equações desenvolvidas foram diferentes entre sexos. Alhassan et al. (1975) mostraram a diferença entre os coeficientes de regressão determinados para animais da raça Angus e Hereford. Também Harpster et al. (1978), citados por Fox \& Black (1984), obtiveram diferentes equações estimando a composição corporal de animais Hereford selecionados e de animais Hereford não selecionados, mostrando a influência do tamanho corporal sobre a composição do corpo vazio. Portanto, a técnica da estimativa da composição corporal a partir do corte da costela é altamente precisa, mas as equações devem ser calculadas para populações específicas, considerando-se que elas poderão ser diferentes entre sexos (Hankins \& Howe, 1946), raças (Alhassan et al., 1975), grupos genéticos (Lanna et al., 1995) ou para animais muito jovens (Pearson et al., 1968).

Assim, este trabalho foi conduzido com o objetivo de estabelecer equações correlacionando a composição química e física das 9-10-11ª costelas com a composição química corporal especificamente para tourinhos da raça Santa Gertrudes.

\section{Material e Métodos}

Quinze tourinhos Santa Gertrudes provenientes do rebanho do Instituto de Zootecnia de São José do Rio Preto foram mantidos confinados entre nove e 15 meses de idade, durante a estação seca. Os animais foram abatidos com pesos diversos, entre 220 e $505 \mathrm{~kg}$, sendo seis abatidos no início do confinamento.

Após jejum de 18 horas, esses animais foram pesados e insensibilizados com auxílio de pistola de pressão, no Instituto de Tecnologia de Alimentos, em Campinas, SP. Em seguida, a jugular foi seccionada para coleta do sangue, que foi descartado após pesagem e coleta de amostras. Após a retirada do couro e das patas, a cabeça foi separada na junção atlanto-occipital. A gordura renal-pélvica-inguinal foi separada da carcaça e pesada. Foram retirados os órgãos (traquéia, pulmão, pâncreas, esôfago, mesentério, coração, baço, fígado, rins, rabo e o pênis) e o tecido gastrintestinal livre de conteúdo (retículo-rúmen, omaso-abomaso e intestinos), que também foram pesados. Em seguida, a carcaça foi dividida em duas metades, que foram pesadas e levadas para a câmara de resfriamento por 48 horas.

A composição do corpo vazio foi determinada diretamente, analisando-se todos os tecidos do animal, além do sangue. Os componentes utilizados 
foram: metade esquerda da carcaça; metade esquerda da cabeça e patas dianteira e traseira esquerda; metade esquerda do couro; e órgãos, tecido gastrintestinal e gordura renal-pélvica-inguinal. A metade esquerda do couro foi pesada e colocada em câmara de resfriamento junto com a meia-carcaça esquerda, e os outros componentes foram acondicionados em sacos plásticos e congelados.

Após congelamento, os componentes foram reduzidos a pedaços menores com auxílio de uma serra de fita, procurando-se evitar perda de tecido. Em seguida, todos os componentes foram moídos utilizando-se um moedor de carne Herman P-33A, com motor de $15 \mathrm{HP}$, até que ficassem em estado pastoso, sendo então retiradas quatro amostras de cada componente de cada animal. O processamento dos componentes foi realizado no Instituto de Zootecnia, em Nova Odessa, SP. A determinação da porcentagem de matéria seca dos componentes e do sangue foi feita por liofilização por aproximadamente 80 horas, e posteriormente as amostras foram novamente moídas em liquidificador com gelo seco.

Em todas as amostras foram determinados os teores de extrato etéreo com aparelho tipo Soxhlet, e extração por 20 horas; de proteína, com aparelho Kjedahl; e minerais, pela queima do material em mufla a $600^{\circ} \mathrm{C}$ por 16 horas (Alleoni et al., 1997). Nas amostras liofilizadas, foi determinada a matéria seca em estufa a $105^{\circ} \mathrm{C}$, após secagem por 18 horas, devido à ocorrência de reabsorção de água, e os resultados obtidos corrigidos para matéria seca total.

Da meia-carcaça direita resfriada, foi retirado o corte das 9-10-11 $1^{\underline{a}}$ costelas, conforme metodologia de Hankins \& Howe (1946). Essa secção foi obtida da seguinte forma: após separação da carcaça entre a $12^{\underline{a}}$ e a $13^{\underline{a}}$ costela, mediu-se a distância entre o ponto onde a vértebra foi seccionada e o início da cartilagem da $12^{\mathrm{a}}$ costela; em seguida, definiu-se um ponto, $61,5 \%$ dessa medida distante da vértebra, e traçou-se uma linha perpendicular nesse ponto, encontrando um outro ponto da interseção dessa linha com a circunferência externa da costela; daí, separou-se a parte dorsal da parte ventral, cortando-se as costelas nesse ponto; e finalmente separaram-se as costelas 9-10-11 , cortando-se com a faca pressionada à face posterior da $8^{\mathrm{a}} \mathrm{e} 11^{\underline{a}}$ costela.

Após a separação do corte, este foi pesado e separado fisicamente em músculo, gordura e ossos. Esses componentes foram, então, pesados separadamente para determinação da composição física do corte. Em seguida foram congelados, e posteriormente moídos conjuntamente, feita homogeneização do material e retiradas amostras para análises químicas, conforme descrito anteriormente.

Os resultados foram utilizados para obter equações de regressão linear simples para estimativa da composição química do corpo vazio (porcentagens de água, proteína, extrato etéreo e minerais) a partir da composição química (porcentagens de água, proteína, extrato etéreo e minerais) e física (porcentagens de músculo, gordura e ossos) do corte das costelas 9-10-11 .

\section{Resultados e Discussão}

As médias, os valores mínimo e máximo e o desvio-padrão de cada variável utilizada para a determinação das equações de regressão são mostrados na Tabela 1.

A porcentagem de minerais no corpo vazio foi semelhante àquelas encontradas por Leme et al. (1994) e Alleoni et al. (1997), que obtiveram 4,4 e $4,5 \%$, respectivamente. Esses autores encontraram, no corpo vazio, teores de proteína de 17,9 e 17,1\%, e de extrato etéreo de 17,9 e $21,1 \%$, respectivamente. Esses valores foram diferentes dos mostrados na Tabela 1, provavelmente porque aqueles autores abateram os animais com idade mais avançada, entre 20 e 30 meses, enquanto os animais deste trabalho foram abatidos entre 9 e 15 meses. A porcentagem de água foi semelhante à encontrada por Leme et al. (1994), que obtiveram 59,6.

Os desvios-padrão encontrados foram baixos e semelhantes aos encontrados por Leme et al. (1994) e Alleoni et al. (1997), com exceção do peso do corpo vazio e da carcaça, uma vez que aqueles autores encontraram valores entre 40 e 56, provavelmente devido à amplitude de pesos dos animais abatidos neste trabalho.

Todas as equações aqui apresentadas são seguidas entre parênteses do coeficiente de determinação $\left(r^{2}\right)$ e do desvio-padrão da estimativa (Sy.x).

$\mathrm{O}$ peso do corpo vazio (PVz) foi estimado a partir do peso da carcaça quente (PCQ), ambas na mesma unidade $(\mathrm{kg})$, tendo sido encontrada a seguinte equação: $\mathrm{PVz}=1,6093 \mathrm{PCQ}+0,6784\left(\mathrm{r}^{2}=0,99 ;\right.$ Sy.x $\left.=6,28\right)$

O coeficiente de determinação obtido para essa equação, de 0,99 , foi alto, demonstrando a possibilidade de utilização dessa equação para tourinhos Santa Gertrudes. Jorge et al. (2000) obtiveram coeficiente de determinação de 0,95 na estimativa do peso do 
Tabela 1 - Médias, valores mínimos e máximos, e desvios-padrão das variáveis

Table 1 - Means, minimum and maximum values, and standard deviations of the variables

\begin{tabular}{|c|c|c|c|c|}
\hline $\begin{array}{l}\text { Parâmetros } \\
\text { Parameters }\end{array}$ & $\begin{array}{l}\text { Média } \\
\text { Mean }\end{array}$ & $\begin{array}{l}\text { Valor mínimo } \\
\text { Minimum value }\end{array}$ & $\begin{array}{l}\text { Valor máximo } \\
\text { Maximum value }\end{array}$ & $\begin{array}{l}\text { Desvio-padrão } \\
\text { Standard deviation }\end{array}$ \\
\hline $\begin{array}{l}\text { Peso do corpo vazio, } \mathrm{kg} \\
\text { Empty body weight, } \mathrm{kg}\end{array}$ & 321,83 & 200,60 & 465,71 & 99,94 \\
\hline $\begin{array}{l}\text { Peso da carcaça quente, } \mathrm{kg} \\
\text { Hot carcass weight, } \mathrm{kg} \\
\text { Corpo vazio }\end{array}$ & 199,56 & 125,80 & 293,10 & 61,99 \\
\hline Empty body & & & & \\
\hline $\begin{array}{l}\text { Água, \% } \\
\text { Water, \% }\end{array}$ & 59,55 & 54,90 & 66,95 & 4,32 \\
\hline $\begin{array}{l}\text { Extrato etéreo, \% } \\
\text { Ether extract, \% }\end{array}$ & 16,17 & 8,35 & 21,90 & 4,54 \\
\hline $\begin{array}{l}\text { Proteína, \% } \\
\text { Protein, } \%\end{array}$ & 20,04 & 18,31 & 22,71 & 1,06 \\
\hline $\begin{array}{l}\text { Minerais, \% } \\
\text { Ash, \% }\end{array}$ & 4,24 & 3,26 & 4,90 & 0,46 \\
\hline $9-10-11$ a costelas & & & & \\
\hline $\begin{array}{l}\text { 9-10-1 } 11^{\text {th }} \text { ribs cut } \\
\text { Água, \% } \\
\text { Water, \% }\end{array}$ & 58,85 & 55,01 & 65,04 & 3,76 \\
\hline $\begin{array}{l}\text { Extrato etéreo, } \% \\
\text { Ether extract, } \%\end{array}$ & 16,79 & 8,43 & 22,91 & 4,90 \\
\hline $\begin{array}{l}\text { Minerais, \% } \\
\text { Ash, \% }\end{array}$ & 4,72 & 3,40 & 5,95 & 0,70 \\
\hline $\begin{array}{l}\text { Músculos, \% } \\
\text { Lean, \% }\end{array}$ & 59,20 & 54,46 & 67,08 & 3,40 \\
\hline $\begin{array}{l}\text { Gordura, \% } \\
\text { Fat, \% }\end{array}$ & 21,93 & 12,62 & 29,68 & 5,29 \\
\hline $\begin{array}{l}\text { Ossos, \% } \\
\text { Bone, \% }\end{array}$ & 18,87 & 14,15 & 23,08 & 2,81 \\
\hline
\end{tabular}

corpo vazio a partir do peso do animal antes do abate. A equação estimando o peso vazio a partir do peso da carcaça está representada graficamente na Figura 1.

Para estimar a porcentagem de água no corpo vazio (\%ÁguaPVz) foram estabelecidas as seguintes equações, correlacionando-a com a porcentagem de água (\%ÁguaCost), de extrato etéreo (\%EECost), de proteína (\%ProtCost) e de minerais (\%MinCost) nas 9-10-11 a costelas, respectivamente:

\%ÁguaPVz $=1,1221 \%$ ÁguaCost $-6,4839\left(\mathrm{r}^{2}=0,95 ;\right.$ Sy. $\left.\mathrm{x}=0,97\right)$ \%ÁguaPVz $=-0,8594 \%$ EECost $+73,9800\left(r^{2}=0,95 ;\right.$ Sy.x $\left.=1,02\right)$ \%ÁguaPVz $=3,5220 \%$ ProtCost $-9,9709\left(\mathrm{r}^{2}=0,70 ;\right.$ Sy. $\left.\mathrm{x}=2,48\right)$ $\%$ ÁguaPVz $=2,5571 \%$ MinCost $+47,4810\left(\mathrm{r}^{2}=0,17 ;\right.$ Sy.x $\left.=4,09\right)$

As equações de porcentagem de água do corpo vazio em função da porcentagem de água e de extrato etéreo do corte da costela foram as mais indicadas, pois apresentaram coeficientes de determinação mais elevados, e a diferença entre esses coeficientes foi pequena. Considerou-se a mais indicada a equação

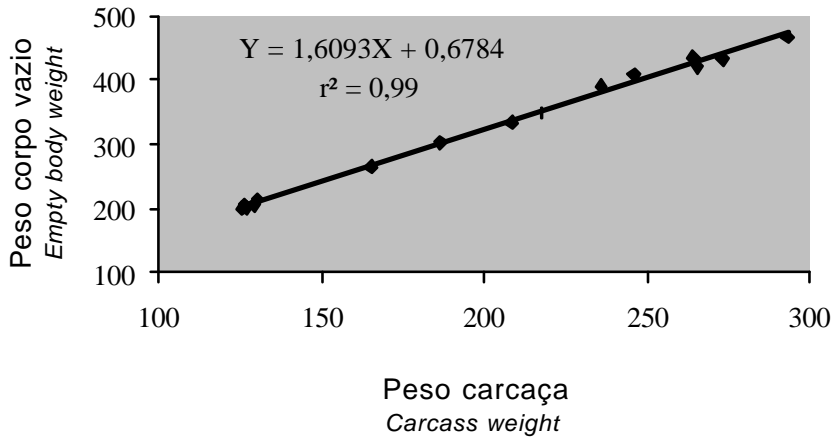

Figura 1 - Relação entre pesos da carcaça quente e do corpo vazio.

Figure 1 - Relation between hot carcass and empty body weights.

que incluiu a porcentagem de água no corte da costela, devido ao menor desvio-padrão, e sua representação gráfica encontra-se na Figura 2. Lanna et al. (1995) recomendaram a equação correlacionando 
a porcentagem de água no corpo vazio a partir da porcentagem de extrato etéreo nas 9-10-11 $\underline{a}$ costelas, para bovinos Nelore.

A equação correlacionando a porcentagem de água do corpo vazio com a porcentagem de minerais do corte da costela não foi adequada para estimativa, devido ao baixo valor do coeficiente de determinação.

Para estimar a porcentagem de extrato etéreo no corpo vazio (\%EEPVz) foram obtidas as seguintes equações a partir da porcentagem de água, extrato etéreo, proteína e minerais nas 9-10-11aㅡ costelas:

$\%$ EEPVz $=-1,1570 \%$ ÁguaCost $+84,2600\left(r^{2}=0,92 ;\right.$ Sy. $\left.x=1,33\right)$ $\%$ EEPVz $=0,8831 \%$ EECost $+1,3431\left(r^{2}=0,91 ;\right.$ Sy.x $\left.=1,42\right)$

$\%$ EEPVz $=-3,6733 \%$ ProtCost $+88,6790\left(r^{2}=0,67 ;\right.$ Sy.x $\left.=2,63\right)$ $\%$ EEPVz $=-2,3821 \%$ MinCost $+27,4150\left(r^{2}=0,13 ;\right.$ Sy.x $\left.=4,38\right)$

A equação que estimou com mais precisão a porcentagem de extrato etéreo no corpo vazio foi aquela em função da porcentagem de água no corte das 9-10-11 a costelas como variável independente. Lanna et al. (1995) obtiveram a melhor equação para estimar a porcentagem de extrato etéreo no corpo vazio a partir da porcentagem de extrato etéreo nas costelas 9-10-11 , com coeficiente de determinação de 0,94. A equação obtida por Jorge et al. (2000) também incluiu as mesmas variáveis, com coeficiente de determinação de 0,88 . As equações correlacionando a porcentagem de extrato etéreo do corpo vazio com as porcentagens de proteína e de minerais no corte da costela também não devem ser utilizadas, pois os coeficientes de determinação não foram adequados.

Por outro lado, os teores de água e de extrato etéreo no corpo vazio foram altamente correlacionados, apresentando maior coeficiente de

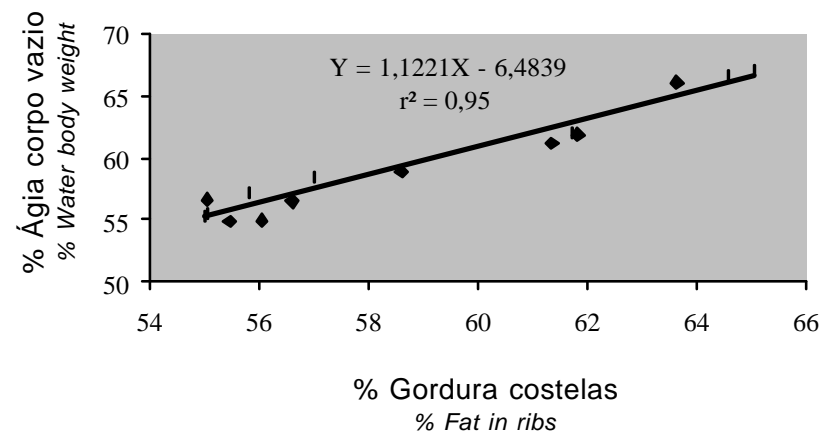

Figura 2 - Relação entre porcentagens de água no corpo vazio e nas costelas 9-10-11a.

Figure 2 - Relation between percentage of water in empty body and 9-10-11 th ribs cut. determinação e menor desvio-padrão que a equação correlacionando a água no corte da costela e o extrato etéreo no corpo vazio. Portanto, a água no corpo vazio poderia ser estimada a partir da porcentagem de água no corte das 9-10-1 1aㅡ costelas, e a porcentagem de extrato etéreo no corpo vazio estimada pela porcentagem de água, também do corpo vazio, conforme a seguinte equação, que está representada graficamente na Figura 3.

$\%$ EEPVz $=-1,0192 \%$ ÁguaPVz $+76,8675\left(\mathrm{r}^{2}=0,94 ;\right.$ Sy.x $\left.=1,12\right)$

A precisão obtida na estimativa da porcentagem de proteína no corpo vazio a partir dos componentes das costelas 9-10-11ª não permitiu a utilização de nenhuma das equações determinadas, pois o maior coeficiente de determinação obtido foi de 0,10 . Esses coeficientes foram considerados baixos, e opostos aos obtidos por Peron et al. (1993), Jorge et al. (2000) e Ferreira et al. (2001), que encontraram, respectivamente, valores de 0,$93 ; 0,84$; e 0,97 para a estimativa da porcentagem de proteína.

As equações estimando a porcentagem de minerais no corpo vazio a partir das porcentagens de água, extrato etéreo, proteína e minerais no corte das 9-10-11 $1^{\underline{a}}$ costelas também não se mostraram eficientes, pois o maior coeficiente de determinação obtido foi de 0,65 .

Assim, as porcentagens de proteína e minerais no corpo vazio, como ocorreu em outros trabalhos (Reid et al., 1955; Garret \& Hinman, 1969; Garret et al., 1971), não apresentaram boas estimativas a partir do corte das 9-10-11 1 costelas, pois o coeficiente de determinação das equações não foi alto na maioria das vezes. Lanna et al. (1995) apresentaram coefici-

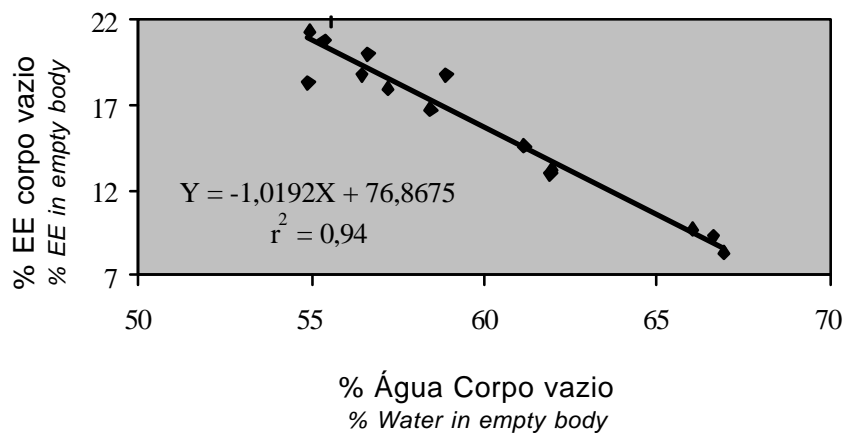

Figura 3 - Relação entre porcentagens de extrato etéreo e água no corpo vazio.

Figure 3 - Relationship between percentage of ether extract and water in empty body.

R. Bras. Zootec., v.32, n.3, p.709-718, 2003 
entes de determinação de 0,43 e 0,23 para a estimativa das porcentagens de proteína e minerais no corpo vazio, respectivamente, a partir da composição do corte das 9-10-11므 costelas.

Essas porcentagens foram então estimadas a partir da composição do corpo vazio desengordurado, ou seja, descontada a porcentagem de extrato etéreo (Reid et al., 1955), e estão apresentadas na Tabela 2.

$\mathrm{Na}$ Tabela 2, verifica-se a possibilidade de estimar as porcentagens de proteína e de minerais no corpo vazio como porcentagens do corpo vazio desengordurado, na matéria original ou seca, pois esses valores são constantes. Na composição química do corpo vazio desengordurado, os teores de água, proteína e minerais não foram semelhantes aos obtidos com animais Nelore por Leme et al. (1994), tendo sido encontrados os valores de 72,7; 21,9; e 5,4\%, respectivamente. As relações proteína:água e minerais:água obtidas por aqueles autores foram 0,30 e 0,07. Pode-se, portanto, inferir que, no corpo desengordurado, podem haver diferenças nas porcentagens de proteína e minerais entre animais de raças, idades e/ou grupamentos genéticos distintos. Os coeficientes lineares para estimativa da composição química do corpo vazio a partir da composição química do corte das costelas foram distintos dos obtidos por Alhassan et al. (1975), com Angus e Hereford, e por Lanna et al. (1995) e Alleoni et al. (1997), com animais da raça Nelore, demonstrando tam- bém que as equações são distintas para diferentes raças e/ou grupamentos genéticos. Portanto, as equações de regressão aqui obtidas devem ser utilizadas para tourinhos Santa Gertrudes, até que sejam testadas para outros grupamentos genéticos, raças ou categorias animais.

Também foram determinadas as equações para estimar a porcentagem de água no peso do corpo vazio a partir da porcentagem de músculo (\%MúscCost), de gordura (\%GordCost), e de ossos (\%OssosCost) nas 9-10-11a costelas, conforme mostrado a seguir:

\%ÁguaPVz $=1,0426 \%$ MúscCost - 2,3737 $\left(\mathrm{r}^{2}=0,78 ;\right.$ Sy.x $\left.=1,96\right)$ \%ÁguaPVz $=-0,6949 \%$ GordCost $+74,5890\left(\mathrm{r}^{2}=0,84 ;\right.$ Sy.x $\left.=1,69\right)$ $\%$ ÁguaPVz $=0,9316 \%$ OssosCost $+41,7710\left(\mathrm{r}^{2}=0,42 ;\right.$ Sy.x $\left.=3,16\right)$

A equação que estimou com mais precisão a porcentagem de água no corpo vazio foi a partir da porcentagem de gordura separável no corte das costelas, representada graficamente na Figura 4, não sendo indicada a estimativa a partir da porcentagem de ossos.

Também foram determinadas as equações estimando a porcentagem de extrato etéreo no corpo vazio a partir dos componentes separáveis dos corte das 9-10-11므 costelas, como mostrado a seguir:

$\% \mathrm{EEPVz}=-1,0518 \%$ MúscCost $+78,6810\left(\mathrm{r}^{2}=0,74 ;\right.$ Sy.x $\left.=2,23\right)$ $\% \mathrm{EEPVz}=0,7189 \%$ GordCost $+0,6491\left(\mathrm{r}^{2}=0,83 ;\right.$ Sy. $\left.\mathrm{x}=1,78\right)$ $\% \mathrm{EEPVz}=-1,0034 \%$ OssosCost $+35,3480\left(\mathrm{r}^{2}=0,46 ;\right.$ Sy. $\left.\mathrm{x}=3,19\right)$

A equação que estimou com mais precisão a

Tabela 2 - Composição do corpo vazio desengordurado e relações entre proteína e água e entre minerais e água, no corpo vazio

Table 2 - Composition of empty body without fat and relationship between protein and water and between ash and water on empty body

\begin{tabular}{|c|c|c|c|c|}
\hline $\begin{array}{l}\text { Parâmetros } \\
\text { Parameters } \\
\end{array}$ & $\begin{array}{l}\text { Média } \\
\text { Mean }\end{array}$ & $\begin{array}{c}\text { Valor mínimo } \\
\text { Minimum value }\end{array}$ & $\begin{array}{c}\text { Valor máximo } \\
\text { Maximum value }\end{array}$ & $\begin{array}{c}\text { Desvio padrão } \\
\text { Standard deviation }\end{array}$ \\
\hline $\begin{array}{l}\text { Água, \% } \\
\text { Water, \% }\end{array}$ & 70,98 & 67,21 & 73,46 & 1,67 \\
\hline Proteína, \% & 23,97 & 21,26 & 27,80 & 1,79 \\
\hline $\begin{array}{l}\text { Protein, \% } \\
\text { Minerais, \% } \\
\text { Ash, \% }\end{array}$ & 5,05 & 4,07 & 5,54 & 0,38 \\
\hline $\begin{array}{l}\text { Proteína, \% MS }{ }^{1} \\
\text { Protein, \% DM }\end{array}$ & 82,52 & 80,14 & 86,05 & 1,83 \\
\hline $\begin{array}{l}\text { Minerais, \% } \mathrm{MS}^{1} \\
\text { Ash, \% } D M^{1}\end{array}$ & 17,48 & 13,95 & 19,86 & 1,83 \\
\hline $\begin{array}{l}\text { Proteína:Água } \\
\text { Protein:Water }\end{array}$ & 0,338 & 0,289 & 0,414 & 0,033 \\
\hline $\begin{array}{l}\text { Minerais:Água } \\
\text { Ash:Water }\end{array}$ & 0,071 & 0,057 & 0,077 & 0,005 \\
\hline
\end{tabular}

${ }^{1} \mathrm{MS}$ - Matéria seca (DM - Dry matter). 


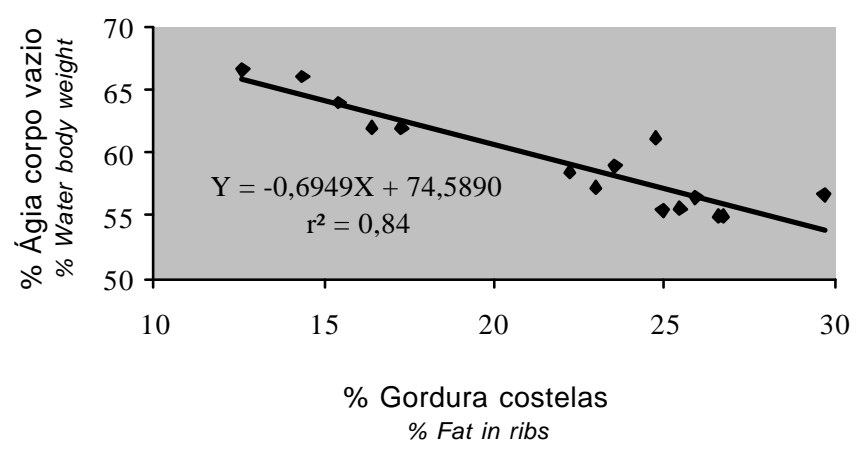

Figura 4 - Relação entre porcentagens de água no corpo vazio e gordura separável nas costelas 9-10-11a.

Figure 4 - Relation between percentage of water in empty body and separable fat in 9-10-1 th $^{\text {th }}$ ribs cut.

porcentagem de extrato etéreo do corpo vazio foi a partir da porcentagem de gordura separável no corte das 9-10-1 1 ${ }^{\mathrm{a}}$ costelas, apresentada graficamente na Figura 5. O coeficiente de determinação obtido foi semelhante aos encontrados por Hankins \& Howe (1946) e Alhassan et al. (1975), que obtiveram 0,84 e 0,85 respectivamente, mas inferiores ao encontrado por Alleoni et al. (1997), que obtiveram 0,94.

As equações obtidas relacionando a porcentagem de proteína no corpo vazio a partir dos componentes separáveis do corte das 9-10-11 $1^{\underline{a}}$ costelas não foram apropriadas na estimativa da porcentagem de proteína no corpo vazio, em função dos baixos coeficientes de determinação $(0,02$ a 0,06$)$.

Foram determinadas as equações relacionando a porcentagem de minerais no corpo vazio (\% MinPVz) e as porcentagens dos componentes separáveis do corte das costelas:

\%MinPVz $=0,0859 \%$ MúscCost $-0,8500\left(\mathrm{r}^{2}=0,43 ;\right.$ Sy.x $\left.=0,35\right)$ $\% \mathrm{MinPVz}=-0,0716 \%$ GordCost $+5,8036\left(\mathrm{r}^{2}=0,72 ;\right.$ Sy.x $\left.=0,24\right)$ $\% \operatorname{MinPVz}=0,1277 \%$ OssosCost $+1,8238\left(r^{2}=0,65 ;\right.$ Sy. $\left.x=0,28\right)$

A porcentagem de gordura separável das costelas 9-10-11 1 ambém foi adequada para estimar a porcentagem de minerais no corpo vazio, e a representação gráfica aparece na Figura 6.

Os resultados obtidos por Alleoni et al. (1997) também demonstraram que a gordura separável do corte das costelas estimou com alta precisão as porcentagens de água e extrato etéreo, $\mathrm{r}^{2}$ de $0,91 \mathrm{e}$ 0,94 respectivamente. Os coeficientes obtidos por esses autores foram mais altos do que os obtidos no presente trabalho, que estão mais próximos aos en-

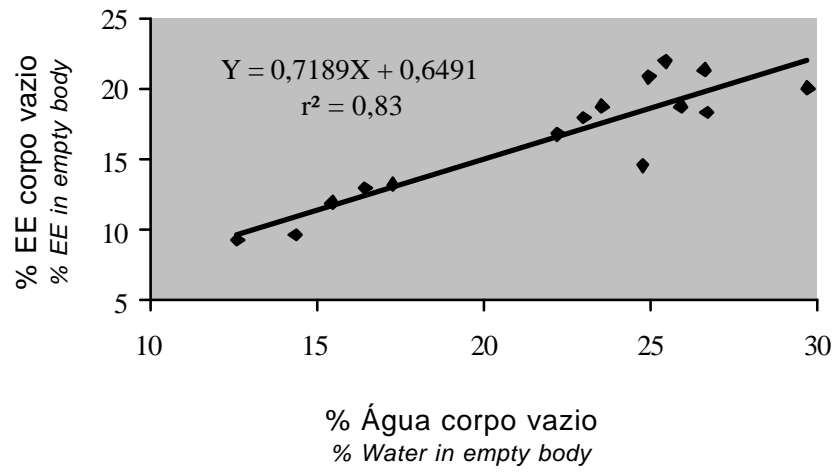

Figura 5 - Relação entre porcentagens de extrato etéreo no corpo vazio e gordura separável nas costelas $9-10-11^{\mathrm{a}}$.

Figure 5 - Relationship between percentage of ether extract in empty body and separable fat in 9-10-1 $1^{\text {th }}$ ribs cut.

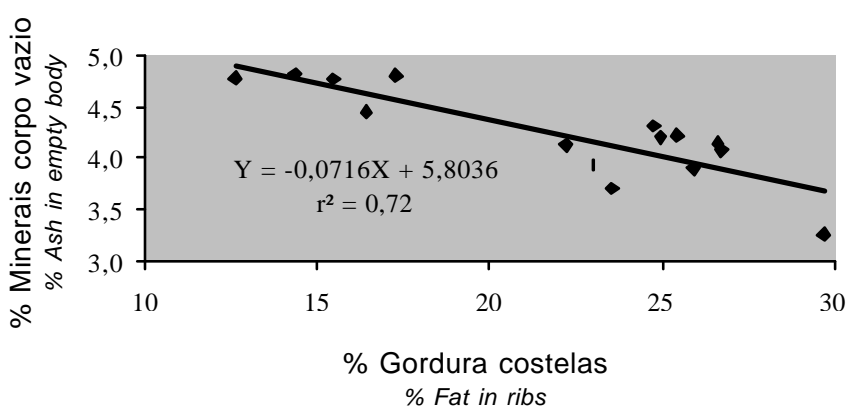

Figura 6 - Relação entre porcentagens de minerais no corpo vazio e gordura separável nas costelas 9-10-11

Figure 6 - Relation between percentage of ash in empty body and separable fat in 9-10-1 ${ }^{\text {th }}$ ribs cut.

contrados por Alhassan et al. (1975), 0,85 e 0,84 respectivamente. Outros autores também demonstraram a alta correlação entre os componentes físicos do corte das costelas e a composição química corporal ou da carcaça. Hopper (1944) obteve coeficientes de determinação acima de 0,90 para a maioria das estimativas.

Como a porcentagem de gordura separável no corte da costela foi eficaz na estimativa da porcentagem de água, de extrato etéreo e de minerais do corpo vazio, a porcentagem de proteína do corpo vazio poderia então ser calculada por diferença.

A estimativa da composição química corporal a partir da composição física do corte das costelas 9-10-11 a mostrou-se uma técnica aplicável, devido aos bons coeficientes de determinação obtidos. Mas 
como os coeficientes de determinação encontrados a partir da composição química do corte da costela foram maiores, indica-se a utilização desse método de determinação indireta da composição química corporal, como também apontado por Lanna et al. (1995). Mais ainda, considerando-se que as porcentagens de água e extrato etéreo no corpo vazio devem ser calculadas utilizando as equações desenvolvidas a partir da porcentagem de água do corte da costela, ficou facilitada a adoção dessa técnica, pois basta a liofilização das amostras, para determinação de todos os nutrientes do corpo vazio, uma vez que as porcentagens de proteína e minerais são calculadas como porcentagens da matéria seca do corpo desengordurado. Não fica invalidada a utilização da composição física da costela para determinação da composição química corporal, como recomendado por Alleoni et al. (1997), em locais onde não haja equipamento adequado para determinação da água nas amostras de corte de costelas, e essa técnica também não depende de laboratórios e reagentes, sendo portanto mais barata e prática.

\section{Conclusões}

A determinação indireta da composição química corporal a partir do corte das 9-10-11 a costelas mostrou-se tecnicamente eficiente, a partir da composição física ou química do corte da costela.

Os teores de água das 9-10-11 1 a costelas e do corpo vazio mostraram-se altamente correlacionados, assim como as porcentagens de água e extrato etéreo no corpo vazio, permitindo boa estimativa da composição química corporal a partir desse corte. O mesmo não ocorreu para os teores de proteína e minerais, que podem ser calculados pela composição do corpo vazio desengordurado.

A gordura separável do corte das 9-10-11 $\underline{a}$ costelas foi eficiente para estimar as porcentagens de água, extrato etéreo e minerais. O mesmo não ocorreu para a estimativa do teor de proteína, que pode ser calculado por diferença.

A utilização da composição química do corte das 9-10-11 - costelas para estimar a composição química corporal deve ser preferida à composição física do corte da costela, necessitando-se apenas da determinação da porcentagem de água para estimar todos os componentes do corpo vazio.

\section{Literatura Citada}

ALHASSAN, W.S.; BUCHANAN-SMITH, J.G.; USBORNE, W.R. et al. Predicting empty body composition of cattle from carcass weight and rib cut composition. Canadian Journal of Animal Science, v.55, p.369-376, 1975.

ALLEONI, G.F.; BOIN, C.; LEME, P.R. et al. Avaliação da composição química e física dos cortes da costela para estimar a composição química corporal de novilhos Nelore. Revista Brasileira de Zootecnia, v.26, n.2, p.382-390, 1997.

ESTRADA, L.H.C.; FONTES, C.A.A.; JORGE, A.M. et al. Exigências nutricionais de bovinos não-castrados em confinamento. 1. Conteúdo corporal e exigências líquidas de proteína e energia para ganho de peso.Revista Brasileira de Zootecnia, v.26, n.3, p.575-583, 1997.

FERREIRA, M.A.; VALADARES FILHO, S.C.; VERAS, A.S.C. et al. Predição da composição corporal por intermédio de método indireto. Revista Brasileira de Zootecnia, v.30, n.1, p.242-246, 2001.

FOX, D.G.; BLACK, J.R. A system for predicting body composition and performance of growing cattle. Journal of Animal Science, v.58, n.3, p.725-739, 1984.

GARRET, W.N.; HINMAN, N. Re-evaluation of the relationship between carcass density and body composition of beef steers. Journal of Animal Science, v.28, n.1, p.1-5, 1969.

GARRET, W.N.; ROLLINS, W.C.; TANAKA, M. et al. Empty body and carcass composition of cattle. Journal of Animal Science, v.33, n.1, p.194, 1971.

HANKINS, O.G.; HOWE, P.E.Estimation of the composition of beef carcasses and cuts. Washington: USDA, 1946. p.1-20. (Technical Bulletin - USDA, 926)

HOPPER, T.H. Methods of estimating the physical and chemical composition of cattle. Journal of Agricultural Research, v.68, n.6, p.239-268, 1944.

JORGE, A.M.; FONTES, C.A.A.; PAULINO, M.F. et al. Utilização de método indireto para predição da composição química corporal de zebuínos. Revista Brasileira de Zootecnia, v.29, n.6, p.1862-1867, 2000.

LANNA, D.P.D.; BOIN, C.; ALLEONI, G.F. et al. Estimation of carcass and empty body composition of Zebu bulls using the composition of rib cuts. Sciencia Agrícola, v.52, n.1, p.189-197, 1995.

LEME, P.R.; BOIN, C.; ALLEONI, G.F. et al. Estimativa da composição química corporal de novilhos Nelore através do espaço de deutério. Revista da Sociedade Brasileira de Zootecnia, v.23, n.3, p.441-452, 1994.

LOFGREEN, G.P.; HULL, J.L.; OTAGAKI, K.K. Estimation of empty body weight of beef cattle. Journal of Animal Science, v.21, n.1, p.20-24, 1962.

LUSH, J.L. Practical methods for estimating the proportion of fat and bone in cattle slaughtered in commercial packing plants. Journal of Agricultural Research, v.32, n.8, p.727-755, 1926.

MACNEIL, M.D. Choice of a prediction equation and the use of the selected equation in subsequent experimentation.Journal of Animal Science, v.57, n.5, p.1328-1336, 1983.

PAULINO, M.F.; FONTES, C.A.A.; JORGE, A.M. et al. Exigências de energia para mantença de bovinos zebuínos nãocastrados em confinamento. Revista Brasileira de Zootecnia, v.28, n.3, p.621-626, 1999.

PEARSON, A.M.; PURCHAS, R.W.; REINEKE, E.P. Theory and potential usefulness of body density as a predictor of body composition. In: NATIONAL ACADEMY OF 
SCIENCES. Body composition in animals and man. Washington: 1968. p.153-169. (Publication, 1598)

PERON, A.J.; FONTES, C.A.A.; LANA, R.P. et al. Predição da composição corporal e da carcaça de bovinos através de métodos indiretos. Revista da Sociedade Brasileira de Zootecnia, v.22, n.2, p.227-237, 1993.

REID, J.T.; WELlington, G.H.; DUNN, H.O. Some relationships among the major chemical components of the bovine body and their application to nutritional investigations. Journal of Dairy Science, v.38, n.12, p.1344-1359, 1955.

REID, J.T.; BENSADOUN, A.; BULL, L.S. et al. Some peculiarities in the body composition of animals. In: NATIONAL ACADEMY OF SCIENCES. Body composition in animals and man. Washington: 1968. p.19-44. (Publication, 1598)
ROBELIN, J.; GEAY, Y. Estimation de la composition des carcasses jeunes bovins a partir de la composition d'un morceau monocostal prélevé au niveau de la $11^{\mathrm{a}}$ côte. I. Composition anatomique de la carcasse. Annales de Zootechnie, v.24, n.3, p.391-402, 1975.

Recebido em: 10/06/02

Aceito em: 18/11/02 